Another glass, used for making the sodium discharge lamp, is remarkable in that it contains no silica. This is in order that it shall withstand the attack of the sodium vapour. Other special glasses have had to be developed in order that suitable wires can be sealed through glass to secure and make contact with the electrodes in thermionic devices; such glasses must have a very high electric resistance. Dr. Partridge's paper was illustrated by an excellent colour film of glass-making operations; this film emphasized the changes in normal procedure entailed in making articles from some of these special glasses.

A paper different from the others, in that it dealt with a new industry which has grown out of the glass industry itself, was presented by Dr. A. De Dani, of Fibre Glass, Ltd. Glass fibres may be drawn as single continuous fibres or by the glass wool process. This process consists in subjecting a stream of glass issuing from a platinum orifice to an intense blast of superheated steam. The stream of glass is thus shattered, resulting in a multitude of very fine fibres of glass. It was thought at one time that the steam shattered the glass into droplets which were then drawn into fibres, but calculations showed that this explanation was not very probable. The process has therefore been investigated using high-speed ciné photography.

Some of the films taken in the experiments were shown to the meeting. The audience was thus able to see an example of industrial research in a new development of the glass industry, thereby completing the review of the many-sided aspects of glass technology-a subject in which physics and chemistry must be applied for a fundamental understanding of the material, in which physics, chemistry, engineering and mathematics are applied in the industrial development, and an industry which, although several thousand years old, is now, with few exceptions, such as high-quality table-ware and decorative pieces and the production in small quantities of special glasses, a fully mechanized industry.

\title{
SEVENTH INTERNATIONAL ASTRONAUTICAL CONGRESS
}

$\mathrm{T}$ HE Seventh International Astronautical Congress was held in Rome this year during September 17-22, and was attended by more than four hundred delegates from many various countries and of equally varied interests. There is, of course, practically no scientific subject which is not involved in astronautics one way or another, and which does not stand to profit from its findings. The proceedings took place in the magnificent Congress Hall of the Espozisione Universale di Roma, and during the two and a half days of technical sessions more than forty papers were presented. An unusual feature-at least for a scientific meeting-was the use of a simultaneous translation service in Italian, French, German and English. Despite the valiant efforts of the Italian linguists providing this service, it would no doubt have been improved had the translators been natives of the country into whose language they translated, and had they had a knowledge of scientific terminology. These stern requirements would seem-necessary to ensure the complete success of such a service.

With so many papers to be presented, only a quarter of an hour was allotted to each speaker, and there was practically no time for formal discussion. This made the task of digesting the contents of many of the lectures difficult, particularly as many of them were not available in printed form. Special interest was aroused by the contributions of the delegation from the United States, who, numbering among them the first professional 'astronautical engineers', introduced an atmosphere of reality unusual in conferences on this subject. With regard to the speculations concerning the relative progress of the American and Soviet attempts to set up an artificial Farth satellite, it is not inappropriate to remark that the only Soviet delegate, Prof. I. I. Sedov, of the U.S.S.R. Academy of Sciences, disclaimed any knowledge of his countrymen's progress in this venture and declined to make any statement on the subject.

The American artificial satellite, or to give it its code name, 'Project Vanguard', formed the subject of many papers. It is to be a three-stage rocket, appearing, however, to be composed of only two stages, because the last stage is carried inside the second. The initial stage is $44 \mathrm{ft}$. long and 45 in. in diameter, and is powered by a liquid oxygen rocket with kerosene as a fuel, and pressurized by helium; it is intended to carry the projectile to a height of 36 miles, and to achieve an all-burnt velocity of $5,500 \mathrm{ft}$. $/ \mathrm{sec}$. The casing of the initial stage, after being jettisoned, is expected to land at a distance of 75 miles from the launching station. The second stage is $32 \mathrm{ft}$. long, and employs a bifuel rocket unit with nitric acid and hydrazine hydrate as propellants, and also pressurized by helium. It is expected to increase its speed to $13,400 \mathrm{ft}$./sec. at all-burnt, when its height would be 140 miles. Besides enclosing the final stage, it contains the control and guidance equipment, which is to be brought into action during a period of coasting flight after the operation of the second-stage rocket, to effect the critical final adjustments to the course of the projectile. The final stage of the rocket is then spin-stabilized, and launched from within the nose of the second. It consists of a solid-fuel rocket mounted on a magnesium alloy sphere, 20 in. in diameter, which is the Earth satellite itself. The final velocity would have to be about $26,000 \mathrm{ft}$. $/ \mathrm{sec}$. and it is anticipated that the perigee of the satellite's orbit would be about three hundred miles from the surface of the Earth. When the casing of the solid rocket is at last jettisoned, about ten minutes will have elapsed since take-off, and the satellite will have travelled some fifteen hundred miles from the launching point.

The projectile is finless, and control on the first two stages is to be obtained by deflecting the rocket venturi on gimbals. A considerable degree of accuracy in both final speed and direction of motion is required if the orbit is to be successfully established. As an example, if there is no error in speed and if the perigee is not to be less than two hundred miles above the Earth, nor the apogee more distant than eight hundred miles, an angular error of about $3^{\circ}$ in 
the direction of motion is all that can be tolerated. On the other hand, if there is no angular error, and the orbit is to be within the same limits, the velocity error must be no more than $\pm 450 \mathrm{ft}$. $/ \mathrm{sec}$. No official commitment on expected accuracy is forthcoming, though it was suggested in discussion that as many as fifty satellites might have to be launched to give a reasonable likelihood that one might be placed in a satisfactory orbit. Precisely what would form a 'satisfactory' orbit, is, in any event, difficult to define. The magnitude of the air density - and so of the drag-at such extreme altitudes is the chief factor governing the useful life-time of the vehicle, but is also one of the unknown properties which it is hoped that observation of the satellite may enable to be evaluated. Tentative estimates put the mean loss in apogee and perigee at (initially) about $250 \mathrm{ft}$. and $200 \mathrm{ft}$. per day, respectively. Because of the Earth's oblateness, the variation in the radius of the apogee and perigee is in fact oscillatory, with a period of forty days and an amplitude of about two miles.

It is hoped that observation of the track of the satellite vehicles may also supply data leading to determinations of the variation of gravitational acceleration, and of the shape of the Earth. In addition, it is hoped to be able to interlock the geodetic networks of the continents more closely than has been possible before. During the initial circuits in the orbit, the satellite can be located by the radio signals it sends out; but as the batteries have only a limited life, later observation will depend on visual and photographic records, when the satellite is visible before dawn or after sunset. In this 'Operation Moonwatch', the help of amateur astronomers all over the world is being enlisted, through the International Astronautical Federation. The track of the satellites takes them eastwards as far south as $45^{\circ}$ latitude on the Greenwich meridian, and north to the same latitude at a longitude of $180^{\circ}$ (so that they will not be visible in Britain). Some other data are to be telemetered from the satellites, though it seems that there is little room for the installation of many instruments. The weight of the satellite is only $21 \frac{1}{2} \mathrm{lb}$. (The complete take-off weight of the three stages is $22,600 \mathrm{lb}$., implying a mass ratio of more than a thousand.) The nature of the observations to be made was not announced, though the possibilities are without limit. High on the list of priorities is the counting of impacts by meteors. This and many other experimental techniques which might be involved are being practised already, and several of the papers presented at the Congress dealt with them.

One of the greatest of the potential hazards to man in space flight is the effect of heavy primary cosmic radiation. More than twenty-five stratosphere balloon flights conducted by the United States Air Force have carried biological specimens to altitudes above $30 \mathrm{~km}$. in geomagnetic latitudes above $55^{\circ}$. Although no somatic health hazard has been observed cver periods of about twenty-four hours-the longest period of exposure obtained-the repeated observation of streaks of grey hair on black mice, 200 in width, has suggested that a so far unidentified mechanism causes wider radial spread of radiation effects (by some 20 times) than has been predicted before. In another paper, details were reported of personal experiences during half-minute periods in a zero-gravity condition. (These were experiments conducted in an aircraft.) The majority of the subjects tested reported as feeling "very comfortable".

Looking still further ahead, another paper discussed the time dilation effect of relativity theory, and its effect on humans travelling in a vehicle moving at speeds near that of light. The general conclusion seemed to be that man's life-time would be effectively increased to such an extent that he can survive outward journeys which in terms of lightyears of distance far exceed his normal life-time.

T. NONWEILER

\section{OBITUARIES}

\section{Prof. J. B. Leathes, F.R.S.}

WITr the death, at Montreux on September 14 at the age of ninety-two, of Prof. John Beresford Leathes, physiology lost another of its dwindling links with the past century. Born on November 5, 1864, the son of a clergyman, and educated at Winchester and New College, Oxford, he also was intended for the Church; but a natural bent for science drew him to the study of medicine, and he qualified M.B. in 1893, and F.R.C.S. a year later, from Guy's Hospital, London.

A talent for chemistry, the teaching of which was a strong feature at Guy's, decided Leathes to follow the applications of chemical knowledge to the elucidation of physiological problems, in pursuit of which plan ho went to work for two years with Drechsel at Berne, and then under Schmiedeberg in Strasbourg. On his return, like Sherrington before him, he was appointed to the lectureship in physiology at St. Thomas's Hospital, where he stayed for some ten years, during the last eight of which he also held a part-time appointment at the Lister Institute, which was one of the main foci of development for the rapidly evolving subject of biochemistry. $\mathrm{He}$ thus became one of that small and devoted band which included C. J. Martin, Harden and Young, Cathcart, Dakin and Raper, who did so much to forward the interests of that subject in its formative years. It was in that stimulating environment that his interest in metabolic problems was aroused, and where his book, "Problems in Animal Metabolism", was produced. His first published papers dealt with body fluids, proteolytic enzymes, protein metabolism, and the fat content of various muscles. Most of his subsequent work had to do with fat metabolism, and in much of this he had the collaboration of H. S. Raper ; their joint monograph on "The Fats" (1910 and 1925) is still a standard work.

In 1909 he became professor of pathological chemistry at Toronto, where he was shortly joined by Raper. During these years he was elected to the fellowship of the Royal Society (1911). In 1915 he went as professor of physiology to Sheffield, in succession to J. S. Macdonald, who had moved to Liverpool, and he remained there until his retirement in 1933. 